\title{
VARIAÇÕES ESTRUTURAIS E FLORÍSTICAS DO CARRASCO NO PLANALTO DA IBIAPABA, ESTADO DO CEARÁ
}

\author{
ARAÚJO, F. S. de, ${ }^{1}$ MARTINS, F. R. ${ }^{2}$ e SHEPHERD, G. J. ${ }^{2}$ \\ ${ }^{1}$ Departamento de Biologia, Centro de Ciências, Universidade Federal do Ceará, Blobo 906, \\ Campus do Pici, CEP 60455-760, Fortaleza, CE, Brasil \\ ${ }^{2}$ Departamento de Botânica, Instituto de Biologia, Universidade Estadual de Campinas, C.P. 6109, \\ CEP 13083-970, Campinas, SP \\ Correspondência para: Francisca Soares de Araújo, Departamento de Biologia, Centro de Ciências, Universidade \\ Federal do Ceará, Blobo 906, Campus do Pici, CEP 60.455-760, Fortaleza, CE, Brasil, e-mail: tchesca@ufc.br \\ Recebido em 19/03/98 - Aceito em 17/11/98 - Distribuído em 22/12/99
}

(Com 4 figuras)

\section{ABSTRACT \\ Variations of structure and of flora of the "carrasco" vegetation of the Ibiapaba plateau, state of Ceará, Brazil}

"Carrasco" is a closed, tall-shrubby, xerophilous vegetation on Quartz Sand soils between altitudes of 700 and $900 \mathrm{~m}$ on Ibiapaba and Araripe plateaus in the Brazilian semi-arid domain. As it is still very poorly known, this paper aims to describe the structure and composition of the woody community and its spatial variation in relation to the soil. One-hundred $10 \times 10 \mathrm{~m}$ plots were located by pairs of random

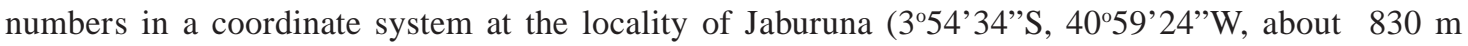
altitude), municipality of Ubajara, north Ibiapaba. All woody plants with a minimum stem diameter of $3 \mathrm{~cm}$ at ground level had their vertical height (not for climbers) and stem perimeter recorded. A soil extract from $0-50 \mathrm{~cm}$ depth was taken at the centre of each plot. Published surveys of other carrasco areas on the south Ibiapaba were considered for comparison. The community structure showed great dominance concentration, the most abundant species (Acacia langsdorffii, Piptadenia moniliformis, Thiloa glaucocarpa) varied between surveys. At Jaburuna $81 \%$ of all sampled plants were shrubs, $14 \%$ trees (the most with less than $10 \mathrm{~cm}$ of trunk diameter and $6 \mathrm{~m}$ height), and $5 \%$ climbers. Canberra distances and Jaccard's Indices were calculated from a primary matrix of 87 species (with 5 or more individuals) and 175 plots. Several methods of cluster analysis were employed, all showed great floristic variation from place to place. A matrix of soil physical and chemical variates per plot was constructed, and the canonical correspondence analysis was applied to both primary and soil matrices. Lower $\mathrm{pH}$ and higher sum of bases (e. g. Brunfelsia cuneifolia, Neojeobertia candoleana), higher content of gross sand (e. g. Acacia glomerosa, Aspidosperma subincanum) and higher content of fine sand (e. g. Aspidosperma discolor, Hymenaea velutina) were the main variates separating species. The floristic richness at Jaburuna was of 74 species, and the surveys showed no difference in Shannon's diversity, which varied from 2.87 to 3.16 nats/individual.

Key words: "carrasco", shrubland, northeastern Brazil, vegetation structure, flora.

\section{RESUMO}

Carrasco é uma vegetação xerófila arbustiva densa alta, ainda pouco conhecida, que ocorre no domínio semi-árido do nordeste do Brasil, sobre Areias Quartzosas distróficas profundas, entre 700 e $900 \mathrm{~m}$ de altitude, no planalto da Ibiapaba e chapada do Araripe. Este trabalho tem por objetivo conhecer a estrutura e a composição da comunidade lenhosa e possíveis relações dessas variações espaciais com variáveis pedológicas. Em Jaburuna ( $3^{\circ} 54^{\prime} 34^{\prime \prime} \mathrm{S}, 40^{\circ} 59^{\prime} 24^{\prime \prime} \mathrm{W}$, cerca de $830 \mathrm{~m}$ de altitude), município de Ubajara, no norte do planalto da Ibiapaba, foram alocadas 100 parcelas de 10 x $10 \mathrm{~m}$, por sorteio 
de pares de números em um sistema de coordenadas. Foram medidos o perímetro do caule no nível do solo e a altura vertical do sistema aéreo de todos os indivíduos lenhosos com diâmetro mínimo de 3 $\mathrm{cm}$, exceto as alturas das trepadeiras. No centro de cada parcela foi retirada uma alíquota de solo entre 0 e $50 \mathrm{~cm}$ de profundidade. Levantamentos publicados do carrasco no sul da Ibiapaba foram usados para comparação. Ocorreu forte concentração de dominância e as espécies Acacia langsdorffii, Piptadenia moniliformis e Thiloa glaucocarpa alternaram-se em abundância nos diferentes levantamentos. Em Jaburuna, 81\% das plantas amostradas foram representadas por arbustos, 14\% por árvores (a maioria com diâmetro do caule $<10 \mathrm{~cm}$ e altura $<6 \mathrm{~m}$ ) e $5 \%$ por trepadeiras. Foram calculados a distância Camberra e o índice de Jaccard a partir de uma matriz primária contendo 87 espécies (com 5 ou mais indivíduos) e 175 parcelas (incluindo dados publicados para o sul da Ibiapaba). As análises de agrupamentos mostraram que o carrasco apresenta grande variação florística no espaço. Foi construída uma matriz com as variáveis físicas e químicas do solo por parcela e feita a análise da correspondência canônica entre a matriz primária e a matriz de solo. Ocorreu associação de espécies com as variáveis edáficas tais como: menor pH e maior soma de bases (por exemplo, Brunfelsia cuneifolia, Neojeobertia candoleana), maior teor de areia grossa (por exemplo, Acacia glomerosa, Aspidosperma subincanum) e maior teor de areia fina (por exemplo, Aspidosperma discolor, Hymenaea velutina). A riqueza florística foi de 74 espécies em Jaburuna e não houve diferença significativa da diversidade de Shannon entre os levantamentos, variando de 2,87 a 3,16 nats/indivíduo.

Palavras-chave: carrasco, arbustaria, nordeste brasileiro, estrutura da vegetação, flora.

\section{INTRODUÇÃOO}

A região nordeste brasileira ocupa uma área de $1.540 .827 \mathrm{~km}^{2}$ (Nimer, 1989), na qual o clima semi-árido abrange aproximadamente $800.000 \mathrm{~km}^{2}$, ou $10 \%$ do território brasileiro (Ab'Sáber, 1974). O relevo predominante tem altitudes inferiores a $500 \mathrm{~m}$ (depressão sertaneja) entre superfícies que atingem cotas altitudinais de $1.000 \mathrm{~m}$, nas elevações de Borborema, Araripe e Ibiapaba, a 1.200 m, na chapada Diamantina. Essas variações altitudinais, associadas à posição no relevo, que ocasiona chuvas de convecção forçada e diminuição da temperatura com a altitude, possibilitam a ocorrência de diferentes tipos de vegetação naquela região. Na área semi-árida, a caatinga é a vegetação xerófila dominante, apresentando variações fisionômicas e florísticas (Romariz, 1974; Ferri, 1980; Andrade-Lima, 1981; Sampaio, 1995; Rizzini, 1997).

Andrade-Lima (1978) referiu-se a um outro tipo vegetacional xerófilo, ocorrente no nordeste do Brasil, denominado "carrasco" ou "catanduva", com predomínio de formas subarbóreas e arbóreas de pequeno porte (3-4 m), em solos arenosos das chapadas da bacia do rio Parnaíba, no Piauí. Segundo aquele autor, tal vegetação, na região de Barreiras, Bahia ocidental, é denominada de "grameal". Andrade-Lima (1978) distinguiu fisiono- micamente o carrasco da caatinga pela alta densidade dos indivíduos lenhosos, que apresentam troncos finos e são uniestratificados e pela quase ausência de Cactáceas e Bromeliáceas. O termo carrasco tem sido usado em todo o Brasil para designar diferentes tipos de vegetação, geralmente arbustiva, em solos pobres em nutrientes, podendo variar de densa a aberta. No nordeste, diferentes autores usam o termo carrasco para referir-se àquela vegetação arbustiva densa xerófila do planalto da Ibiapaba e chapada do Araripe, ou a um tipo de cerrado denso na Bahia, ou a alguns tipos de caatingas arbustivas em solos pedregosos.

Figueiredo (1986) considerou o carrasco como uma formação vegetal individualizada, constituída por espécies próprias e por outras oriundas de outras formações geograficamente próximas, como a floresta, o cerrado e a caatinga, ocorrendo no reverso do planalto da Ibiapaba e na chapada do Araripe. Baseando-se em alguns elementos da flora e em observações fisionômicas, Fernandes (1990) e Fernandes \& Bezerra (1990) afirmaram ser aquela vegetação procedente da degradação parcial do cerradão, assumindo o aspecto de uma capoeira densa. Comparando a flora lenhosa do carrasco, da caatinga e do cerrado no nordeste, Araújo et al. (1998a) não conseguiram definir se o carrasco seria um tipo de caatinga ou cerrado. 
Mas, através da análise de agrupamento, a partir de uma matriz de dados binários, composta por áreas de caatinga e carrasco, Araújo et al. (1998b) concluíram que o carrasco do planalto da Ibiapaba não seria um tipo de caatinga.

Não há, ainda, consenso entre os autores sobre a conceituação fitogeográfica do carrasco do planalto da Ibiapaba e chapada do Araripe. Seria um tipo próprio de vegetação, como afirmaram Andrade-Lima (1978) e Figueiredo (1986), diferente dos demais tipos de vegetação regional, como a caatinga, a floresta e o cerrado? Ou seria uma variação fisionômica de um daqueles tipos de vegetação, em decorrência de condições muito especiais do relevo, clima e solo? Ou seria uma vegetação ecotonal entre o cerradão, a floresta seca e a caatinga? Ou seria resultante de uma degradação (capoeira) do cerradão, como afirmaram Fernandes (1990) e Fernandes \& Bezerra (1990)? Tais questões decorrem do pouco conhecimento da composição florística, da estrutura comunitária e de suas variações espaciais na vegetação de carrasco, bem como do quase total desconhecimento do tipo de ambiente em que tal vegetação ocorre e das variáveis ambientais de maior influência. Como abordar tais questões, de modo a permitir uma conceituação fitogeográfica mais objetiva da vegetação de carrasco do nordeste? Um meio de propiciar dados que possam fundamentar uma discussão objetiva é através de estudos que passam pelas etapas de: a) descrições quantitativas do ambiente, da flora e da estrutura da vegetação em vários trechos de sua ocorrência; b) comparação quantitativa de dados levantados em vários trechos, de modo a conhecer a amplitude das variações da vegetação e de seu ambiente; e c) associação quantitativa das variações da vegetação a possíveis fatores abióticos, representativos do clima, solo e relevo, admitidos como variáveis de grande influência sobre a vegetação.

Poucas descrições quantitativas da composição e da estrutura da vegetação do carrasco do nordeste foram publicadas. As existentes descrevem estudos desenvolvidos no sul do planalto da Ibiapaba (Araújo et al., 1988a, b). Descrições quantitativas de outros trechos da vegetação de carrasco e sua comparação permitem entender suas variações no espaço e possibilitam conceituá-la de modo mais objetivo. A vegetação de carrasco parece ocorrer exclusivamente sobre solos de
Areias Quartzosas no planalto da Ibiapaba, mas sob climas com grandes diferenças no total anual médio de chuvas (Araújo \& Martins, 1999). Porém, a baixa densidade da rede de estações meteorológicas atualmente existentes na região do planalto da Ibiapaba não permite estabelecer associação estatística das variações da pluviometria com variações da vegetação de carrasco. Por outro lado, sabe-se que variáveis edáficas exercem grandes influências nas variações da vegetação do cerrado (Furley \& Ratter, 1988), mas não se sabe se (nem se conhece como) podem influenciar nas variações da vegetação do carrasco. Este trabalho tem por objetivo contribuir a um melhor conhecimento da vegetação de carrasco no planalto da Ibiapaba, através da: a) descrição da estrutura e composição florística de seu componente lenhoso no norte daquele planalto, b) comparação com descrições de trechos estudados no sul do planalto, de modo a conhecer suas variações no espaço; e c) avaliação da possível influência de variáveis edáficas nessas variações, de modo a conhecer se e como o solo pode influir na distribuição espacial das espécies e de sua abundância.

\section{MATERIAL E MÉTODOS}

\section{Área de estudo}

A área amostrada situa-se ao redor das coordenadas 3'54'34's e 4059'24'W, em altitudes em torno de $830 \mathrm{~m}$, na localidade de Jaburuna, município de Ubajara, no norte do planalto da Ibiapaba, na divisa entre os estados do Ceará e Piauí (Fig. 1). Os solos são areias quartzosas distróficas profundas. São muito friáveis mesmo úmidos, não plásticos e não pegajosos. Têm textura arenosa, são excessivamente drenados, a capacidade de retenção de água é muito baixa e são extremamente ácidos.

O horizonte A pode atingir até $30 \mathrm{~cm}$, com coloração bruno-escura e o horizonte $\mathrm{C}$ é muito profundo, estendendo-se além dos $200 \mathrm{~cm}$, com coloração clara (SUDEC, 1980). As temperaturas médias anuais no alto reverso imediato do planalto da Ibiapaba, no estado do Ceará, estão na faixa de $22^{\circ}$ a $24^{\circ} \mathrm{C}$ e variam muito pouco entre localidades e durante o ano (Lins, 1978). A precipitação média anual no posto de Tianguá, situado na transição floresta-carrasco, distando aproximadamente $20 \mathrm{~km}$ em linha reta da área estudada, é de $1.289 \mathrm{~mm}$ (FUNCEME, 1995). 


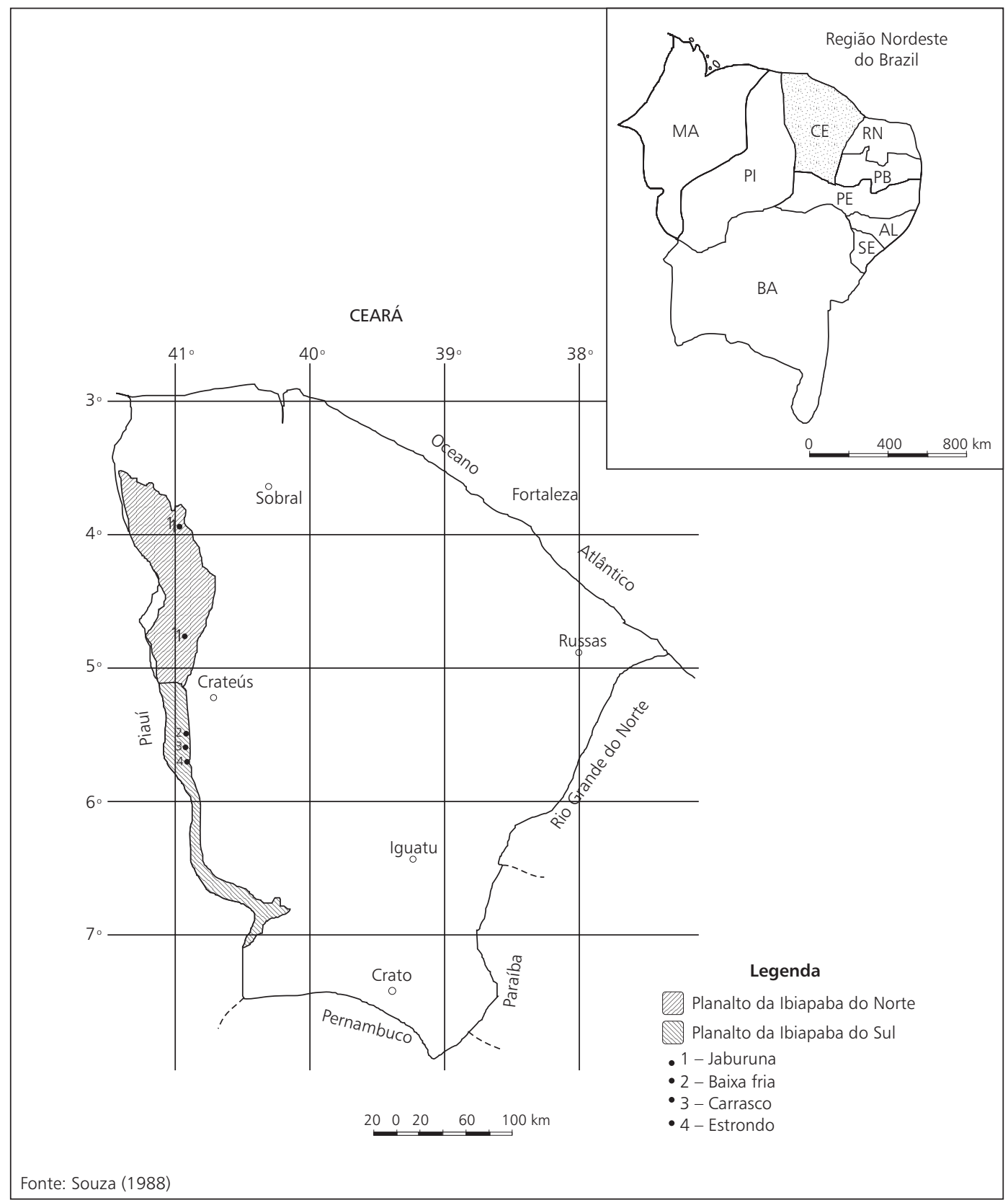

Fig. 1 - Localização das áreas de carrasco estudadas no planalto da Ibiapaba, estado do Ceará.

Em outras áreas de carrasco mais distantes, como Carnaubal (FUNCEME, 1995) e Poranga (SUDENE, 1990), a precipitação anual média é de 667,6 e $675,8 \mathrm{~mm}$, respectivamente.

A área estudada, em Ubajara, está situada entre as isoietas de 1.000 a $1.200 \mathrm{~mm}$, com chuvas de verão-outono e precipitação máxima concentrada em fevereiro, março e abril, resultante dos deslocamentos sazonais da Convergência Intertropical (CIT). Durante três meses do ano a precipitação é menor que $1 \%$ do total anual (Lins, 1978). 


\section{Levantamento da estrutura do componente lenhoso}

Foi utilizado o método de parcelas (MuellerDombois \& Ellenberg, 1974), com dimensões de 10 x $10 \mathrm{~m}$, bastante usado no nordeste em estudos quantitativos da caatinga (Gomes, 1979; Fonseca, 1991; Rodal, 1992) e do carrasco (Araújo et al., 1998b). Foram alocadas aleatoriamente 100 parcelas, totalizando 1 hectare, em um sistema com um eixo $\mathrm{Y}=400 \mathrm{~m}$ na direção $\mathrm{E}-\mathrm{W}$ e um eixo $\mathrm{X}=$ $200 \mathrm{~m}$ na direção S-N. Usando os eixos como um sistema de coordenadas, as parcelas foram localizadas através do sorteio de pares de números. Foram incluídos todos os indivíduos lenhosos com diâmetro do caule no nível do solo, igual ou maior a $3 \mathrm{~cm}$. As trepadeiras lenhosas enraizadas nas parcelas também foram amostradas, por estarem entre as espécies de maior IVI no carrasco estudado por Araújo et al. (1998b). Foram medidos o perímetro do caule no nível do solo, a altura vertical das plantas no interior da parcela ou que tocaram por dentro ou por fora a linha de limite em dois lados da parcela. As plantas que tocaram por dentro ou por fora a linha de limite dos dois outros lados da parcela foram desprezadas. As medidas do perímetro foram tomadas com fita métrica e as alturas, com uma régua. Não foram medidas as alturas das trepadeiras.

\section{Coleta do solo}

No centro de cada parcela foi retirada uma alíquota de 0 a $50 \mathrm{~cm}$ de profundidade do solo, incluindo o horizonte $\mathrm{A}$ e parte do $\mathrm{C}$. As análises físicas e químicas foram feitas no Departamento de Ciências do Solos da Universidade Federal do Ceará, de acordo com EMBRAPA (1979). Os resultados das análises físicas e químicas das amostras de solo foram discutidos por Araújo \& Martins (1999). As variáveis edáficas consideradas neste presente estudo foram textura (areia grossa, areia fina, silte e argila), $\mathrm{pH}$ e soma de bases.

\section{Coleta e identificação do material botânico}

O material coletado das espécies amostradas nas parcelas foi depositado no herbário EAC da Universidade Federal do Ceará, com duplicatas no herbário UEC da Universidade Estadual de Campinas. A identificação foi realizada por comparação com material já identificado e, principalmente, confirmada e complementada por especialistas da Universidade Estadual de Campinas, Instituto de Botânica de São Paulo, Universida- de de São Paulo, Jardim Botânico do Rio de Janeiro, além de outros especialistas do Brasil e do exterior.

\section{Estrutura da vegetação}

Foi analisada através da estrutura de abundância e de tamanho (Martins, 1991). Na estrutura de abundância, foram calculados os parâmetros relativos de densidade, freqüência e dominância (Curtis \& McIntosh,1950; Stearns, 1951) e o índice do valor de importância IVI (Curtis \& McIntosh, 1951), usando o programa FITOPAC (Shepherd, 1995). Como hábito das espécies, foram considerados: a) arbustos, as plantas que apresentavam ramificações do caule abaixo de $50 \mathrm{~cm}$; b) árvores, as que apresentavam caule indiviso, com a copa na parte terminal do caule; c) trepadeiras, as que se apoiavam em suportes, enlaçando-os; e d) subescandentes, as que apresentavam caules decumbentes ou apoiando-se em suportes. Na estrutura de tamanho, as variações de altura e diâmetro das diferentes populações no carrasco de Jaburuna foram comparadas através de diagramas de caixa, em inglês "box plots" (Sokal \& Rohlf, 1995).

\section{Comparação de dados}

Para analisar as variações florísticas e da abundância das espécies e suas relações com variações do solo, foi construída uma matriz quantitativa, contendo 87 espécies lenhosas e 175 parcelas, sendo 100 de Jaburuna e 75 dos três trechos de carrasco estudados por Araújo et al. (1998b), que usou 25 parcelas para amostrar cada trecho da vegetação. As espécies foram consideradas descritores e as parcelas, objetos. Foram consideradas apenas as espécies que ocorreram com cinco ou mais indivíduos. Para analisar variações florísticas no espaço, foi calculada a distância Canberra, excluindo as ausências duplas,

$$
\mathrm{C}=\frac{1}{\mathrm{n}}\left[\sum_{\mathrm{i}-1}^{\mathrm{n}} \frac{\left|\mathrm{X}_{\mathrm{ij}}-\mathrm{X}_{\mathrm{ik}}\right|}{\mathrm{X}_{\mathrm{ij}}+\mathrm{X}_{\mathrm{ik}}}\right]
$$

em que: $\mathrm{C}=$ coeficiente de dissimilaridade entre as amostras j e $\mathrm{k}, \mathrm{n}=$ número de espécies na amostra e $\mathrm{X}_{\mathrm{ij}}, \mathrm{X}_{\mathrm{ik}}=$ número de indivíduos da espécie i em cada amostra (Krebs, 1989). Para verificar se a abundância das espécies estaria ou não influenciando no resultado das distâncias entre as amostras, foi calculado o índice de similaridade de Jaccard $\left(S_{j}=a /(a+b+c)\right)$, em que: $a=$ núme- 
ro de espécies comuns às amostras $\mathrm{A}$ e B, b = número de espécies exclusivas de $\mathrm{B}$ e $\mathrm{c}=$ número de espécies exclusivas de A. Foram feitas várias análises de agrupamentos, usando os métodos de ligação mínima, de ligação completa, da média ponderada (WPGMA) e da média de grupo (UPGMA) (Krebs, 1989), a partir da matriz de distâncias e da matriz de similaridades. Para essas análises foi usado o programa FITOPAC (Shepherd, 1995). Para verificar se as variações florísticas e estruturais da vegetação estariam associadas a variáveis edáficas, consideraram-se variáveis texturais (areia grossa, areia fina, argila e silte) e químicas ( $\mathrm{pH}$ e soma de bases $\mathrm{S}$ ). Essas variáveis edáficas foram selecionadas dentre todas as demais porque apresentaram as maiores variações, tanto em um mesmo trecho quanto entre trechos diferentes da vegetação. As variáveis texturais foram consideradas como indicativas de condições hídricas e as variáveis químicas, como indicativas da capacidade de fertilidade. Na comparação com outros trechos da vegetação de carrasco, foram consideradas as 150 alíquotas coletadas por Araújo et al. (1998b), no sul da Ibiapaba. Araújo et al. (1998b) extraíram as alíquotas das profundidades de 0 a15 cm e de 15 a $45 \mathrm{~cm}$, no centro de cada uma das 75 parcelas. Tais alíquotas incluíram também o horizonte A e parte do C. Calculouse a média de cada variável nas duas profundidades, de modo que cada variável edáfica do sul da Ibiapaba foi representada como uma média da camada superficial de 0 a $45 \mathrm{~cm}$ do solo. Foi, então, construída uma matriz contendo os valores das variáveis edáficas em cada uma das 175 parcelas. Com a matriz quantitativa das espécies e a matriz das variáveis edáficas foi feita a análise de correspondência canônica (CCA), usando o programa CANOCO (ter Braak, 1987-1992). Para diminuir o efeito das espécies dominantes, foi feita transformação logarítmica $(\ln (\mathrm{y}+1)$, em que y = número de indivíduos da espécie) da matriz de espécies.

\section{Diversidade}

Foi calculado o índice de Shannon (H') para espécies (Magurran, 1988), usando o logaritmo neperiano. Cada uma das três amostras estudadas por Araújo et al. (1998b) tinha uma área de 0,25 ha. Para comparar a diversidade da vegetação, foram sorteadas 25 parcelas da amostra de Jaburuna para obter uma área amostral $(0,25$ ha) igual à usada por Araújo et al. (1998b). As quatro amostras de 0,25 ha foram comparadas duas a duas pelo teste $t$, proposto por Hutcheson (1970). Para obter um nível de significância final $(\alpha)$ de $5 \%$ para as 4 amostras foi usado o método de Bonferroni ( $\alpha^{\prime}=\alpha / \mathrm{k}$, em que $\mathrm{k}=4$ comparações), considerando $\alpha^{\prime}=0,01$ em cada comparação (Sokal \& Rohlf, 1995).

\section{RESULTADOS E DISCUSSÃO}

\section{Estrutura de abundância}

$\mathrm{Na}$ amostra de 1 ha foram encontrados 4.408 indivíduos, sendo 4.254 indivíduos vivos e 226 (5\%) mortos ainda em pé. Os 4.254 indivíduos vivos pertenciam a 74 espécies de 30 famílias. Acacia langsdorffii, Piptadenia moniliformis, Guapira graciliflora, Sebastiania brevifolia, Bauhinia acuruana, Aspidosperma multiflorum e Luehea candicans apresentaram densidades relativas maiores que $4 \%$, contribuindo com $54 \%$ do total de indivíduos (Tabela 1). Acacia langsdorffii contribuiu com 23,58\% do número total de indivíduos amostrados, seguida por Piptadenia moniliformis com apenas $6,65 \%$. A maioria (71,6\% das espécies) contribuiu com menos de $1 \%$ da densidade relativa. Entre estas, Bocoa decipiens, uma população numerosa no carrasco de Jaburuna, foi amostrada com um pequeno número de indivíduos devido ao critério de inclusão, que selecionou apenas os indivíduos de maior porte. Em uma amostra, podem ser encontrados dois tipos de espécies raras: as raras virtuais cujo pequeno número na amostra decorre do método (indivíduos de pequeno porte cujo tamanho máximo está próximo ao critério de inclusão); e as raras reais, espécies com poucos indivíduos na comunidade, que não seriam amostrados em maior número, mesmo mudando o critério de inclusão. Allophyllus sp., Capsicum sp., Cereus jamacaru, Chrysophyllum marginatum, Chomelia cf. obtusa, Croton pulegiodosus, Eriope sp., Guapira laxa, Hymenaea velutina, Manilkara cf. triflora, Sapium glandulatum, Stachytarpheta coccinea, Stillingia uleana e Wedelia villosa (Tabela 1) podem ser consideradas raras reais na comunidade de carrasco estudada. Essas espécies foram amostradas com, no máximo, dois indivíduos, indicando que sua densidade média seria ao redor de dois indivíduos por hectare. Espécies que ocorrem na comunidade com uma densidade média de até dois indivíduos por hectare são consideradas raras e colocam muitos problemas importantes de conservação e evolução (Shafer, 1990). 
TABELA 1

Número de indivíduos (n) amostrados com diâmetro do caule igual ou maior que $\mathbf{3} \mathrm{cm}$ no nível do solo em 1 ha, parâmetros de abundância e hábito de espécies lenhosas no carrasco em Jaburuna, município de Ubajara, CE.

\begin{tabular}{|c|c|c|c|c|c|c|c|}
\hline (Código) Espécies & Família & Hábito & $\mathbf{n}$ & $\begin{array}{c}\text { DeR } \\
(\%)\end{array}$ & $\begin{array}{c}\text { DoR } \\
(\%)\end{array}$ & $\begin{array}{c}\text { FeR } \\
(\%)\end{array}$ & IVI \\
\hline ( 1 ) Acacia langsdorffii Benth. & Mimosaceae & arbusto* & 1003 & 23,58 & 15,77 & 6,22 & 45,56 \\
\hline ( 2 ) Piptadenia moniliformis Benth. & Mimosaceae & árvore* & 283 & 6,65 & 14,73 & 5,07 & 26,45 \\
\hline ( 3 ) Guapira graciliflora (Mart. ex J.A.Schmidt) Lundell & Nyctaginaceae & arbusto & 237 & 5,57 & 4,59 & 5,34 & 15,50 \\
\hline ( 4 ) Apuleia grazielana Afr.Fern. & Caesalpiniaceae & arbusto & 168 & 3,95 & 6,43 & 4,53 & 14,90 \\
\hline ( 5 ) Aspidosperma multiflorum A.DC. & Apocynaceae & árvore* & 180 & 4,23 & 6,62 & 3,72 & 14,57 \\
\hline ( 6 ) Luehea candicans Mart. \& Zucc. & Tiliaceae & arbusto* & 176 & 4,14 & 6,02 & 3,78 & 13,94 \\
\hline ( 7 ) Eugenia aff. dysenterica DC. & Myrtaceae & arbusto* & 148 & 3,48 & 5,77 & 3,99 & 13,23 \\
\hline ( 8 ) Sebastiania brevifolia (Müll.Arg.) Müll.Arg. & Euphorbiaceae & arbusto* & 221 & 5,20 & 3,25 & 4,73 & 13,18 \\
\hline (9) Bauhinia acuruana Moric. & Caesalpiniaceae & arbusto* & 193 & 4,54 & 1,39 & 5,20 & 11,13 \\
\hline (10) Croton tricolor Müll.Arg. & Euphorbiaceae & arbusto* & 144 & 3,39 & 4,94 & 2,03 & 10,35 \\
\hline (11) Dalbergia frutescens (Vell.) Britt. & Fabaceae & arbusto* & 149 & 3,50 & 1,82 & 4,46 & 9,78 \\
\hline (12) Croton argyrophylloides Müll.Arg. & Euphorbiaceae & arbusto* & 135 & 3,17 & 1,89 & 4,05 & 9,12 \\
\hline (13) Machaerium stipitatum Vogel & Fabaceae & arbusto* & 107 & 2,52 & 3,54 & 3,04 & 9,09 \\
\hline (14) Arrabidea dispar Bureau ex K.Schum. & Bignoniaceae & trepadeira & 132 & 3,10 & 1,18 & 3,92 & 8,20 \\
\hline (15) Byrsonima gardneriana A.Juss. & Malpighiaceae & arbusto & 62 & 1,46 & 3,10 & 2,09 & 6,65 \\
\hline (16) Pterocarpus villosus Mart. & Fabaceae & arbusto* & 106 & 2,49 & 2,06 & 1,96 & 6,51 \\
\hline (17) Rollinia leptopetala R.E.Fr. & Annonaceae & arbusto* & 62 & 1,46 & 1,45 & 2,64 & 5,55 \\
\hline (18) Jacaranda jasminoides (Thunb.) Sandwith & Bignoniaceae & arbusto* & 68 & 1,60 & 0,83 & 2,64 & 5,06 \\
\hline (19) Manihot brachypoda Müll.Arg. & Euphorbiaceae & arbusto* & 51 & 1,20 & 0,48 & 2,91 & 4,58 \\
\hline (20) Thiloa glaucocarpa (Mart.) Eichler & Combretaceae & árvore & 30 & 0,71 & 2,32 & 1,22 & 4,24 \\
\hline (21) Zanthoxylum hamadriadicum Pirani & Rutaceae & arbusto* & 43 & 1,01 & 0,81 & 2,23 & 4,05 \\
\hline (22) Eugenia piauhiensis O.Berg & Myrtaceae & árvore* & 55 & 1,29 & 0,83 & 1,89 & 4,01 \\
\hline (23) Neea obovata Spruce ex Heimerl & Nyctaginaceae & árvore & 33 & 0,78 & 2,08 & 0,95 & 3,80 \\
\hline (24) Colubrina cordifolia Reissek & Rhamnaceae & arbusto* & 39 & 0,92 & 0,42 & 1,89 & 3,22 \\
\hline (25) Campomanesia aromatica Griseb. & Myrtaceae & arbusto* & 33 & 0,78 & 0,68 & 1,62 & 3,08 \\
\hline (26) Sebastiania sp. & Euphorbiaceae & arbusto* & 34 & 0,80 & 1,07 & 0,95 & 2,81 \\
\hline (27) Erythroxylum cf citrifolium A.St.-Hil. & Erythroxylaceae & arbusto* & 35 & 0,82 & 0,69 & 1,22 & 2,73 \\
\hline (28) Cordia rufescens A.DC. & Boraginaceae & arbusto* & 23 & 0,54 & 0,18 & 1,35 & 2,07 \\
\hline (29) Mansoa schwackei Bureau \& K.Schum. & Bignoniaceae & trepadeira & 32 & 0,75 & 0,28 & 0,95 & 1,97 \\
\hline (30) Platypodium elegans Vogel & Fabaceae & arbusto* & 24 & 0,56 & 0,51 & 0,81 & 1,88 \\
\hline (31) Bocoa decipiens R.S.Cowan & Fabaceae & arbusto* & 22 & 0,52 & 0,17 & 1,15 & 1,83 \\
\hline (32) Dioclea violacea Mart. ex Benth. & Fabaceae & trepadeira & 20 & 0,47 & 0,34 & 1,01 & 1,83 \\
\hline (33) Cnidoscolus vitifolius Pohl & Euphorbiaceae & arbusto & 14 & 0,33 & 0,27 & 0,81 & 1,41 \\
\hline (34) Gochnatia blanchetiana (DC.) Cabrera & Asteraceae & arbusto & 4 & 0,09 & 0,89 & 0,14 & 1,12 \\
\hline (35) Croton nepetaefolius Baill. & Euphorbiaceae & arbusto & 12 & 0,28 & 0,19 & 0,61 & 1,08 \\
\hline (36) Arrabidea chica (Humb. \& Bonpl.) Verl. & Bignoniaceae & trepadeira & 11 & 0,26 & 0,10 & 0,61 & 0,96 \\
\hline
\end{tabular}

Código refere-se à representação da espécie nos diagramas de caixa (Fig. 2). * Pode apresentar indivíduos subescandentes. DeR,

DoR e FeR: densidade, dominância e frequiência relativas (em \%). IVI, índice do valor de importância. 
TABELA 1 (Continuação)

\begin{tabular}{|c|c|c|c|c|c|c|c|}
\hline (Código) Espécies & Família & Hábito & $\mathbf{n}$ & $\begin{array}{l}\text { DeR } \\
(\%)\end{array}$ & $\begin{array}{l}\text { DoR } \\
(\%)\end{array}$ & $\begin{array}{l}\text { FeR } \\
(\%)\end{array}$ & IVI \\
\hline (37) Eugenia flavescens DC. & Myrtaceae & arbusto & 11 & 0,26 & 0,12 & 0,47 & 0,85 \\
\hline (38) Croton zehnteneri Pax \& Roffm. & Euphorbiaceae & arbusto & 10 & 0,24 & 0,12 & 0,47 & 0,83 \\
\hline (39) Senna gardneri (Benth.) H.S.Irwin \& Barneby & Caesalpiniaceae & arbusto & 9 & 0,21 & 0,07 & 0,54 & 0,82 \\
\hline (40) Helicteres velutina K.Schum. & Sterculiaceae & arbusto & 9 & 0,21 & 0,16 & 0,41 & 0,78 \\
\hline (41) Ipomoea brasiliana (Choisy) Meisn. & Convolvulaceae & trepadeira & 7 & 0,16 & 0,11 & 0,47 & 0,75 \\
\hline (42) Trigonia bahiensis E.F.Guim., Miguel \& Fontella & Trigoniaceae & trepadeira & 10 & 0,24 & 0,10 & 0,41 & 0,74 \\
\hline (43) Eugenia lutescens Cambess. & Myrtaceae & arbusto & 9 & 0,21 & 0,07 & 0,41 & 0,69 \\
\hline (44) Hymenaea eriogyne Benth. & Caesalpiniaceae & arbusto & 8 & 0,19 & 0,13 & 0,34 & 0,66 \\
\hline (45) Neojobertia candolleana Bureau \& K.Schum. & Bignoniaceae & trepadeira & 10 & 0,24 & 0,06 & 0,34 & 0,63 \\
\hline (46) Machaerium acutifolium Vogel & Fabaceae & árvore* & 7 & 0,16 & 0,22 & 0,14 & 0,52 \\
\hline (47) Lamiaceae (indet.) & Lamiaceae & arbusto* & 9 & 0,21 & 0,10 & 0,20 & 0,51 \\
\hline $\begin{array}{l}\text { (48) Senna macranthera var. pudibunda (Benth.) } \\
\text { H.S.Irwin \& Barneby }\end{array}$ & Caesalpiniaceae & arbusto & 5 & 0,12 & 0,05 & 0,34 & 0,51 \\
\hline (49) Manihot coerulescens Müll.Arg. & Euphorbiaceae & arbusto & 4 & 0,09 & 0,16 & 0,20 & 0,46 \\
\hline (50) Brunfelsia cuneifolia F.A.Schmidt & Solanaceae & arbusto & 5 & 0,12 & 0,04 & 0,27 & 0,43 \\
\hline (51) Senna barnebyana Afr.Fern. & Caesalpiniaceae & arbusto & 4 & 0,09 & 0,05 & 0,27 & 0,42 \\
\hline (52) Psidium apendiculatum Kiaerskou & Myrtaceae & arbusto & 4 & 0,09 & 0,05 & 0,27 & 0,41 \\
\hline (53) Turnera blanchetiana Urb. & Turneraceae & arbusto* $^{*}$ & 4 & 0,09 & 0,02 & 0,27 & 0,39 \\
\hline (54) Bauhinia sp. & Caesalpiniaceae & arbusto & 5 & 0,12 & 0,04 & 0,20 & 0,36 \\
\hline (55) Maytenus sp.2 & Celastraceae & arbusto & 3 & 0,07 & 0,07 & 0,20 & 0,34 \\
\hline (56) Hymenaea velutina Ducke & Caesalpiniaceae & árvore & 2 & 0,05 & 0,12 & 0,14 & 0,31 \\
\hline (57) Senna trachypus (Benth.) H.S.Irwin \& Barneby & Caesalpiniaceae & arbusto & 3 & 0,07 & 0,04 & 0,20 & 0,31 \\
\hline (58) Solanum sp. & Solanaceae & arbusto & 3 & 0,07 & 0,03 & 0,20 & 0,31 \\
\hline (59) Sapium glandulatum (Vell.) Pax & Euphorbiaceae & árvore & 2 & 0,05 & 0,04 & 0,14 & 0,22 \\
\hline (60) Actinostemon sp. & Euphorbiaceae & trepadeira & 2 & 0,05 & 0,03 & 0,14 & 0,21 \\
\hline (61) Eriope sp (nova) & Lamiaceae & arbusto & 2 & 0,05 & 0,03 & 0,14 & 0,21 \\
\hline (62) Wedelia villosa Gardner & Asteraceae & arbusto & 2 & 0,05 & 0,03 & 0,14 & 0,21 \\
\hline (63) Malpighiaceae (indet.) & Malpighiaceae & trepadeira & 2 & 0,05 & 0,02 & 0,14 & 0,20 \\
\hline (64) Capsicum sp. & Solanaceae & arbusto & 2 & 0,05 & 0,01 & 0,14 & 0,19 \\
\hline $\begin{array}{l}\text { (65) Chrysophyllum marginatum (Hook \& Arn) Radlk. } \\
\text { ssp. marginatum }\end{array}$ & Sapotaceae & arbusto & 2 & 0,05 & 0,01 & 0,14 & 0,19 \\
\hline (66) Cereus jamacaru DC. & Cactaceae & arbusto & 1 & 0,02 & 0,09 & 0,07 & 0,18 \\
\hline (67) Stillingia uleana Pax \& Hoffm. & Euphorbiaceae & arbusto & 2 & 0,05 & 0,01 & 0,07 & 0,13 \\
\hline (68) Allophyllus sp. & Sapindaceae & arbusto & 1 & 0,02 & 0,03 & 0,07 & 0,12 \\
\hline (69) Chomelia cf. obtusa Cham.\& Schltdl. & Rubiaceae & arbusto & 1 & 0,02 & 0,02 & 0,07 & 0,11 \\
\hline (70) Strychnos rubiginosa DC. & Loganiaceae & trepadeira & 1 & 0,02 & 0,02 & 0,07 & 0,11 \\
\hline (71) Croton pulegiodosus Müll.Arg. & Euphorbiaceae & arbusto & 1 & 0,02 & 0,01 & 0,07 & 0,10 \\
\hline (72) Guapira laxa (Netto) Furlan & Nyctaginaceae & arbusto & 1 & 0,02 & 0,01 & 0,07 & 0,10 \\
\hline (73) Manilkara cf. triflora (Allemão) Monach. & Sapotaceae & arbusto & 1 & 0,02 & 0,01 & 0,07 & 0,10 \\
\hline (74) Stachytarpheta coccinea Schauer. & Verbenaceae & arbusto & 1 & 0,02 & 0,01 & 0,07 & 0,10 \\
\hline Total / 74 & 30 & - & 4254 & 100 & 100 & 100 & 299,9 \\
\hline
\end{tabular}


Assim, não se pode concluir que uma espécies é rara com base apenas em sua ocorrência na amostra, mas deve se observar sua distribuição na vegetação real.

Acacia langsdorffii e Piptadenia moniliformis também apresentaram as maiores dominâncias relativas $(15,77 \%$ e $14,73 \%$, respectivamente, Tabela 1). Embora Piptadenia moniliformis tenha apresentado menos de $1 / 3$ da densidade relativa de Acacia langsdorffii, as dominâncias relativas foram semelhantes devido aos maiores diâmetros de Piptadenia moniliformis (Fig. 2).

Acacia langsdorffii em Baixa Fria, Thiloa glaucocarpa em Carrasco e Piptadenia monili- formis em Estrondo foram as espécies que apresentaram maiores densidades e dominâncias relativas (Araújo et al., 1998b). Thiloa glaucocapa apresentou baixa densidade relativa $(0,67 \%) \mathrm{em}$ Jaburuna, mas as outras duas espécies foram muito abundantes, indicando que elas pertencem ao grupo das espécies lenhosas codominantes (Cain \& Castro, 1959) nas áreas de carrasco do planalto da Ibiapaba. Em nossas viagens de campo (Araújo et al., 1998), observamos que aquelas duas espécies podem ocorrer com grande abundância também em locais perturbados, indicando que são sociologicamente importantes em diferentes estádios sucessionais do carrasco.
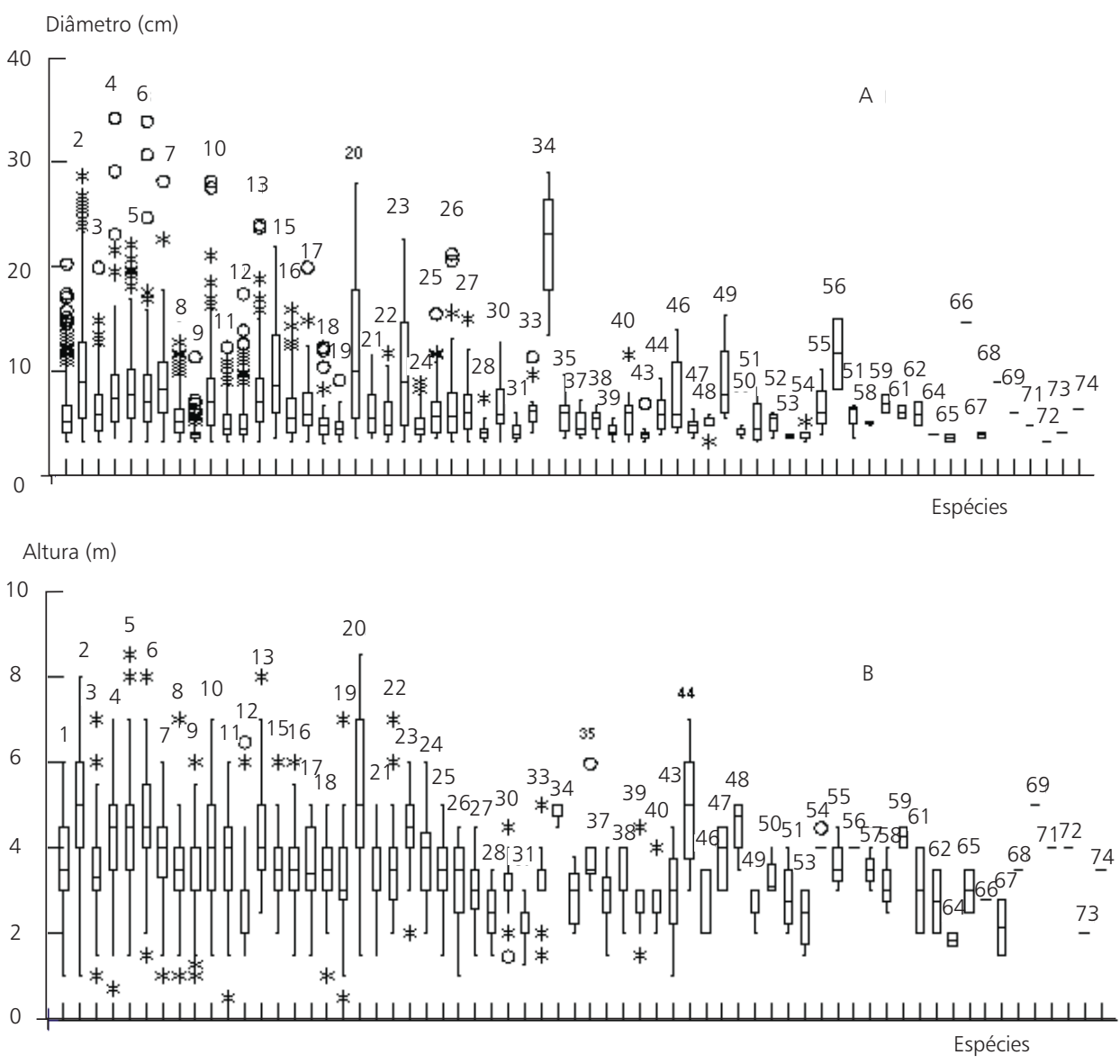

Fig. 2 - Diagrama de caixa (A) dos diâmetros basais $(\geq 3 \mathrm{~cm})$ e (B) das alturas de espécies arbustivas e arbóreas do carrasco em Jaburuna, município de Ubajara, CE. Cada caixa contém os dois quartis (50\%) centrais da distribuição; a linha horizontal dentro de cada caixa representa a mediana; as linhas verticais indicam os quartis extremos, superior e inferior, representando a amplitude. * Pontos extremos e o muito extremos da distribuição. Os números referem-se aos códigos das espécies na Tabela 1. 
Mais da metade (56\%) do índice do valor de importância (IVI) concentrou-se em apenas nove (12\% do total amostrado) espécies: Acacia langsdorffii, Piptadenia moniliformis, Guapira graciliflora, Apuleia grazielana, Aspidosperma multiflorum, Luehea candicans, Eugenia aff. dysenterica, Sebastiania brevifolia e Bauhinia acuruana (Tabela 1).

Exceto Apuleia grazielana, Luehea candicans e Sebastiania brevifolia, que só ocorreram em Jaburuna, as demais espécies também ocorreram com grandes valores de importância nas áreas de Baixa Fria, Carrasco e Estrondo, estudadas por Araújo et al. (1998b).

Tal como essas áreas, a de Jaburuna também mostrou que um pequeno número de espécies (ao redor de $10 \%$ do total amostrado) detém mais de $50 \%$ do número total de indivíduos e da área basal, indicando uma grande concentração de dominância (baixa equabilidade). Por outro lado, os valores de freqüência relativa foram, em geral, menores que os de densidade relativa, indicando que a maior parte das populações mais abundantes tem tendência a um padrão espacial agregado.

\section{Estrutura de tamanho}

A maioria das espécies (81\%) apresentou diâmetros máximos inferiores a $20 \mathrm{~cm}$. Apenas 14 espécies (19\%) apresentaram diâmetros acima de $20 \mathrm{~cm}$, dentre elas Byrsonima gardneriana, Gochnatia blanchetiana, Neea obovata, Piptadenia moniliformis e Thiloa glaucocarpa (Fig. 2A). Predominaram indivíduos com até $10 \mathrm{~cm}$ de diâmetro, de modo semelhante ao observado no carrasco no sul da Ibiapaba (Araújo, 1992). Apenas 13 espécies (20\%, excluídas as trepadeiras) apresentaram indivíduos com alturas superiores a $6 \mathrm{~m}$ (Fig. 2B), entre as quais Aspidosperma multiflorum, Thiloa glaucocarpa, Croton tricolor, Apuleia grazielana, Machaerium acutifolium, Machaerium stipitatum, Piptadenia moniliformis e Luehea candicans. As 13 espécies compõem os elementos arbóreos que ficam dispersos entre as populações predominantemente arbustivas cujas alturas estão concentradas entre 2 e 6 m (Fig. 2B). As áreas do sul da Ibiapaba (Araújo, 1992) apresentaram maiores proporções de espécies com indivíduos acima de 6 m (30\%, $66 \%$ e $68 \%$ em Baixa Fria, Carrasco e Estrondo, respectivamente). Em Jaburuna, Baixa Fria, Carrasco e Estrondo, $8 \%$ (5), $2 \%$ (1), $26 \%$ (14) e $22 \%$
(11) das espécies eram mesofanerófitas (Raunkiaer, 1934), isto é, tinham indivíduos com $8 \mathrm{~m}$ ou mais de altura. Dada a pequena proporção de mesofanerófitas, o carrasco pode ser considerado uma vegetação arbustiva microfanerofítica.

\section{Variações florísticas entre trechos da vegetação}

Tanto as análises de agrupamentos quanto as de ordenação (CCA) apresentaram resultados semelhantes. A coerência nos resultados indica que há grupos florísticos diferentes entre trechos diferentes da vegetação de carrasco na Ibiapaba. Devido à semelhança dos resultados fornecidos pelos diferentes tipos de análise de agrupamentos, optou-se pela apresentação apenas do dendrograma construído através do método da média de grupo (UPGMA).

As amostras da vegetação formaram quatro grandes conjuntos de parcelas, cada qual correspondente a um dos quatro trechos de carrasco estudados (Fig. 3). Dos quatro conjuntos de amostras, Baixa Fria e Estrondo apresentaram menor distância Canberra (dissimilaridade), mas a distância foi muito grande (e a similaridade, pequena) entre todas as áreas, indicando que ocorrem grandes variações na composição florística e na estrutura de abundância, de um local a outro.

Essa variabilidade florística e estrutural decorre de variações espaciais na abundância e na distribuição das espécies e pode estar associada a variações do ambiente. Nos trechos estudados de carrasco, a grande dissimilaridade entre as áreas não foi devida tanto a variações na abundância das espécies, mas principalmente à baixa similaridade florística entre os trechos (Fig. 3). Isso significa que há uma grande variação na distribuição das espécies no espaço.

O carrasco ocupa uma faixa estreita ao longo do planalto da Ibiapaba, que se estende de norte a sul, na divisa entre os estados do Ceará e Piauí. No norte do planalto, o carrasco limita-se a leste com a Floresta Sub-Perenifólia Tropical PlúvioNebular (floresta úmida serrana); no sul, com a floresta Subcaducifólia Tropical Pluvial (floresta seca), ambas situadas na vertente leste do planalto (Figueiredo, 1986). Na área de transição entre a floresta úmida serrana e o carrasco, ocorre ainda uma pequena mancha de cerrado, no município de Guaraciaba do Norte, em altitudes em torno de $900 \mathrm{~m}$. 


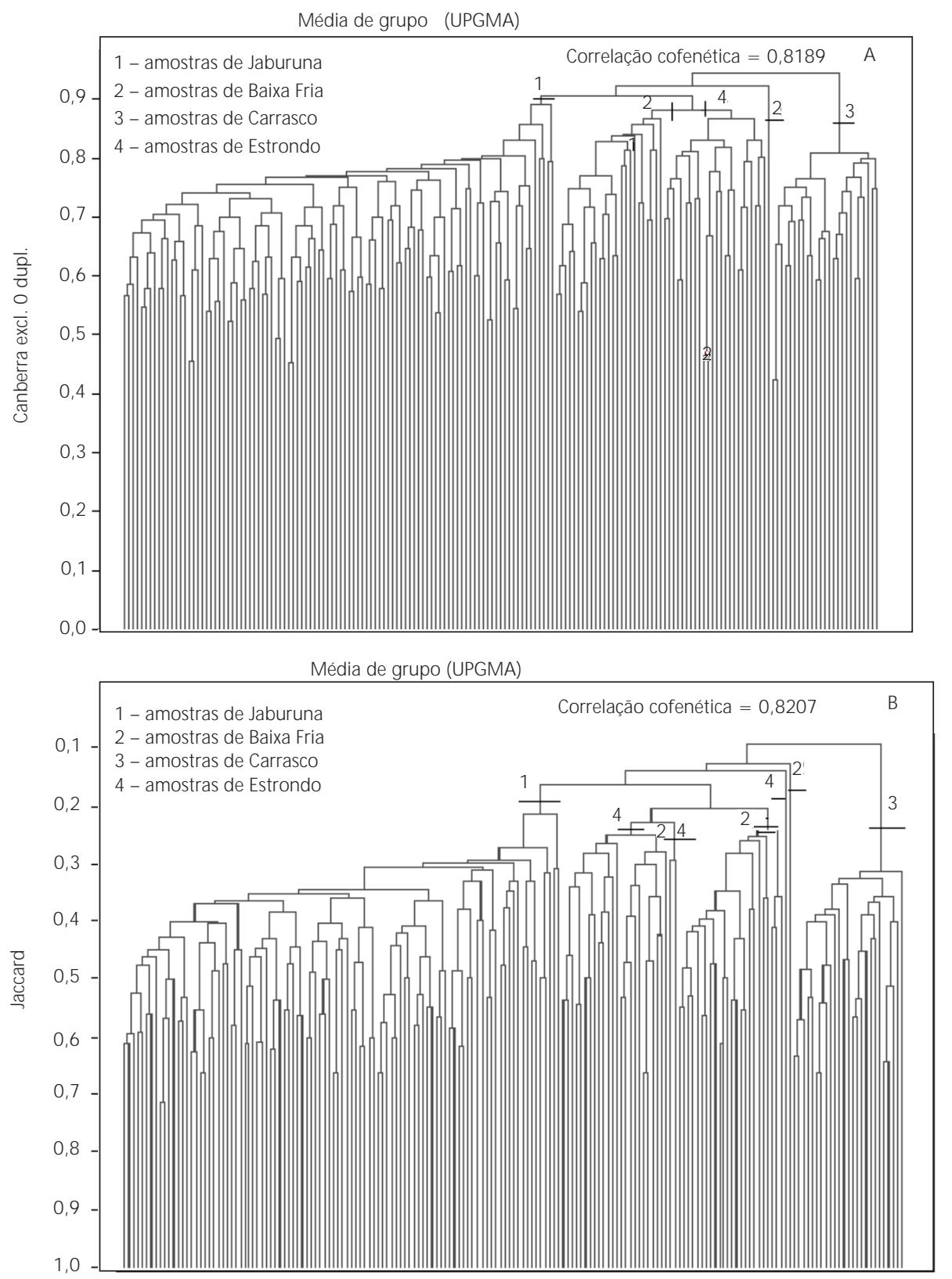

Fig. 3 - (A) Distância e (B) similaridade florística entre as quatro áreas de carrasco estudadas no planalto da Ibiapaba, CE.

A amostra de Carrasco foi a mais diferente (maior distância com as demais amostras, Fig. 3) porque apresentou maior número de espécies também presentes na caatinga (Araújo et al., 1998b).

Isso indica que a variabilidade florística do carrasco pode estar relacionada à presença de espécies da vegetação limítrofe, cuja amplitude ecológica permita a existência em clima e solo menos favoráveis (espécies da floresta) ou em aridez menos acentuada e solos mais pobres (espécies da caatinga). Embora a variância acumulada da análise de correspondência canônica (CCA, Fig. 4) tenha explicado apenas $13 \%$ da variância to- 
tal dos dados das espécies (Tabela 2), a disposição das parcelas na ordenação (Fig. 4) foi semelhante à observada no dendograma da Fig. 3. As parcelas de Jaburuna separaram-se das de Baixa Fria, Carrasco e Estrondo pela maior acidez e maior $\mathrm{S}$ (soma de bases) do solo. As parcelas de Baixa Fria e Carrasco separaram-se de Estrondo pela textura (Fig. 4). Acacia glomerosa, Aspidosperma subincanum, Dalbergia cearensis, Myrcia guianensis, Paulinia cearensis, Pavonia glazioviana, Tabebia serratifolia e Vernonia rugulosa associaram-se a solos com maior teor de areia grossa (Fig. 4, Tabela 3). Bauhinia sp., Brunfelsia cuneifolia, Erythroxylum cf. citrifolium, Eugenia lutescens e Neojeobertia candolleana associaram-se à maior acidez e maior S do solo. Aspidosperma discolor, Hymenaea velutina, Lindackeria ovata, Solanum baturitense e Vitex cymosa foram associadas a solos com maior teor de areia fina (Fig. 4, Tabela 3). Como a variância acumulada na CCA explicou apenas $13 \%$ da variância total dos dados das espécies, é possível que as variações florísticas e estruturais encontradas no carrasco estejam associadas também a outras variáveis, além das edáficas. Entre essas outras possíveis variáveis influentes, devese considerar a maior ou a menor proximidade geográfica com outros tipos de vegetação e variações climáticas, especialmente da pluviometria, devido à posição que a vegetação de carrasco pode ocupar no relevo em relação aos ventos.

\section{Riqueza e diversidade de espécies}

$\mathrm{Na}$ amostra total de 1 ha em Jaburuna, foram encontradas 74 espécies de 30 famílias, das quais 64 arbustivas ou arbóreas e 10 trepadeiras (Tabela 1). Na subamostra de 0,25 ha no mesmo local, encontraram-se 52 espécies de 26 famílias. Nas três amostras de 0,25 ha estudadas por Araújo et al. (1998b), foram encontradas 49, 54 e 49 espécies de 24, 27 e 21 famílias, em Baixa Fria, Carrasco e Estrondo, respectivamente. A riqueza florística foi muito semelhante entre as três amostras de Araújo (1992) e a subamostra de Jaburuna. Isso indica que a menor riqueza florística encontrada nas áreas do sul deve-se, provavelmente, ao tamanho da área amostral.

TABELA 2

Resumo do resultado da análise de correspondência canônica (CCA) das amostras de vegetação e solo no carrasco do planalto da Ibiapaba, $\mathrm{CE}$.

\begin{tabular}{|l|c|c|c|c|}
\hline \multirow{2}{*}{ Resumo } & \multicolumn{3}{|c|}{ Eixos } & \multirow{2}{*}{ Inércia total } \\
\cline { 2 - 5 } & $\mathbf{1}$ & $\mathbf{2} \mathbf{0}$ & $\mathbf{3}$ & \\
\hline Autovalores & 0,403 & 0,188 & 0,099 & - \\
\hline Correlação espécies / variáveis pedológicas & 0,873 & 0,772 & 0,613 & - \\
\hline Percentagem acumulada da variância dos dados das espécies & 7,1 & 10,4 & 12,2 & - \\
\hline Percentagem acumulada da variância da relação espécies/variáveis pedológicas & 53,9 & 79,0 & 92,3 & - \\
\hline Soma de todos os autovalores & - & - & - & 5,663 \\
\hline Soma de todos os autovalores canônicos & - & - & - & $0,747(13 \%)$ \\
\hline
\end{tabular}

TABELA 3

Espécies do carrasco do planalto da Ibiapaba, CE, e seus respectivos códigos representados na Fig. 4 (E, F).

\begin{tabular}{|c|l|c|l|}
\hline 1 & Acacia glomerosa Benth. & 45 & Eugenia piauhiensis O.Berg. \\
\hline 2 & Acacia langsdorffii Benth. & 46 & $\begin{array}{l}\text { Guapira graciliflora } \text { (Mart. ex J.A.Schmidt) } \\
\text { Lundell }\end{array}$ \\
\hline 3 & Allophyllus sericeus (Cambess.) Radlk. & 47 & Helicteres velutina K.Schum. \\
\hline 4 & Apuleia grazielana Afr.Fern. & 48 & Hymenaea eriogyne Benth. \\
\hline 5 & Arrabidea chica (Humb. \& Bonpl.)Verl. & 49 & Hymenaea velutina Ducke \\
\hline 6 & Arrabidea dispar Bureau ex K.Schum & 50 & Ipomoea brasiliana (Choisy) Meisn. \\
\hline
\end{tabular}


TABELA 3 (Continuação)

\begin{tabular}{|c|c|c|c|}
\hline Código & Espécies & Código & Espécies \\
\hline 7 & Aspidosperma discolor A.DC. & 51 & Jacaranda jasminoides (Thunb.) Sandwith \\
\hline 8 & Aspidosperma multiflorum A.DC. & 52 & Lamiaceae (indet.) \\
\hline 9 & Aspidosperma subincanum A.DC. & 53 & Lindackeria ovata (Benth.) Gilg \\
\hline 10 & Bauhinia acuruana Moric. & 54 & Luehea candicans Mart. \& Zucc. \\
\hline 11 & Bauhinia subclavata Benth. & 55 & Machaerium acutifolium Vogel \\
\hline 12 & Bauhinia sp. & 56 & Machaerium stitpitatum Vogel \\
\hline 13 & Mansoa schwackei Bureau \& K.Schum. & 57 & Manihot brachyloda Müll.Arg. \\
\hline 14 & Bocoa decipiens R.S.Cowan & 58 & Maytenus sp. 1 \\
\hline 15 & Bredemeyera brevifolia (Benth.) Klotzsch ex Benn. & 59 & Myrcia guianensis (Aublet) DC. \\
\hline 16 & Brunfelsia cuneifolia F.A.Schmidt & 60 & Neea obovata Spruce ex Heimerl \\
\hline 17 & Byrsonima gardneriana A.Juss. & 61 & $\begin{array}{l}\text { Neojobertia candolleana Bureau \& } \\
\text { K.Schum. }\end{array}$ \\
\hline 18 & Campomanesia aromatica (Aublet) Griseb. & 62 & Paullinia cearensis Somner \& Ferrucci \\
\hline 19 & Capparis flexuosa $(\mathrm{L}.) \mathrm{L}$. & 63 & Pavonia glazioviana Gürke \\
\hline 20 & Cenostigma macrophylum Tul. & 64 & Peixotoa jussieuana Mart. ex A.Juss. \\
\hline 21 & Chomelia cf. obtusa Cham.\& Schltdl. & 65 & Piptadenia moniliformis Benth. \\
\hline 22 & $\begin{array}{l}\text { Chrysophyllum marginatum (Hook. \& Arn.) Radlk. } \\
\text { ssp. marginatum }\end{array}$ & 66 & Platypodium elegans Vogel \\
\hline 23 & Cnidoscolus vitifolius Pohl & 67 & Psidium sartorianum (O.Berg) Nied \\
\hline 24 & Colubrina cordifolia Reissek & 68 & Pterocarpus villosus Mart. \\
\hline 25 & Copaifera martii Hayne & 69 & Rollinia leptopetala R.E.Fr. \\
\hline 26 & Cordia rufescens A.DC. & 70 & Sapium glandulatum (Vell.) Pax \\
\hline 27 & Croton argyrophylloides Müll.Arg. & 71 & Sebastiania brevifolia (Müll.Arg.) Müll.Arg. \\
\hline 28 & Croton jacobinensis Müll.Arg. & 72 & Sebastiania sp. \\
\hline 29 & Croton nepetaefolius Baill. & 73 & Senna barnebyana Afr.Fern. \\
\hline 30 & Croton tricolor Müll.Arg. & 74 & $\begin{array}{l}\text { Senna gardneri (Benth.) H.S.Irwin \& } \\
\text { Barneby }\end{array}$ \\
\hline 31 & Croton zehnteneri Pax \& Roffm. & 75 & $\begin{array}{l}\text { Senna macranthera var. pudibunda (Benth.) } \\
\text { H.S.Irwin \& Barneby }\end{array}$ \\
\hline 32 & Dalbergia cearensis Ducke & 76 & Senna trachypus (Benth.) H.S.Irwin \& Barneby \\
\hline 33 & Dalbergia frutescens (Vell.) Britt. & 77 & Solanum baturitense Huber \\
\hline 34 & Dioclea violacea Mart. ex Benth. & 78 & Strychnos rubiginosa DC. \\
\hline 35 & Ephedranthus pisocarpus $\mathrm{R}$. E. Fr. & 79 & Swartzia flaemingi Raddi \\
\hline 36 & Erythroxylum barbatum O.E.Schultz & 80 & Tabebuia serratifolia (Vahl) Nicholson \\
\hline 37 & Erytroxylum cf. citrifolium A.St.-Hil. & 81 & Thiloa glaucocarpa (Mart.) Eichler \\
\hline 38 & Erythroxylum laetevirens O.E.Schulz & 82 & $\begin{array}{l}\text { Trigonia bahiensis E.F.Guim., Miguel \& } \\
\text { Fontella }\end{array}$ \\
\hline 39 & Erythroxylum cf. nummularia Peyritsch & 83 & $\begin{array}{l}\text { Turbina cordata (Choisy) D.F.Austin \& } \\
\text { Staples }\end{array}$ \\
\hline 40 & Eugenia lutescens Cambess. & 84 & Turnera blanchetiana $\mathrm{Urb}$. \\
\hline 41 & Eugenia flavescens DC. & 85 & Vernonia rugulosa Sch.Bip. ex Baker \\
\hline 42 & Eugenia aff. dysenterica DC. & 86 & Vitex cymosa Bert. ex Spreng. \\
\hline 43 & Eugenia aff. ligustrina $(\mathrm{Sw}$.$) Willd.$ & 87 & Zanthoxylum hamadriadicum Pirani \\
\hline 44 & Eugenia punicifolia (Kunth) DC. & & \\
\hline
\end{tabular}



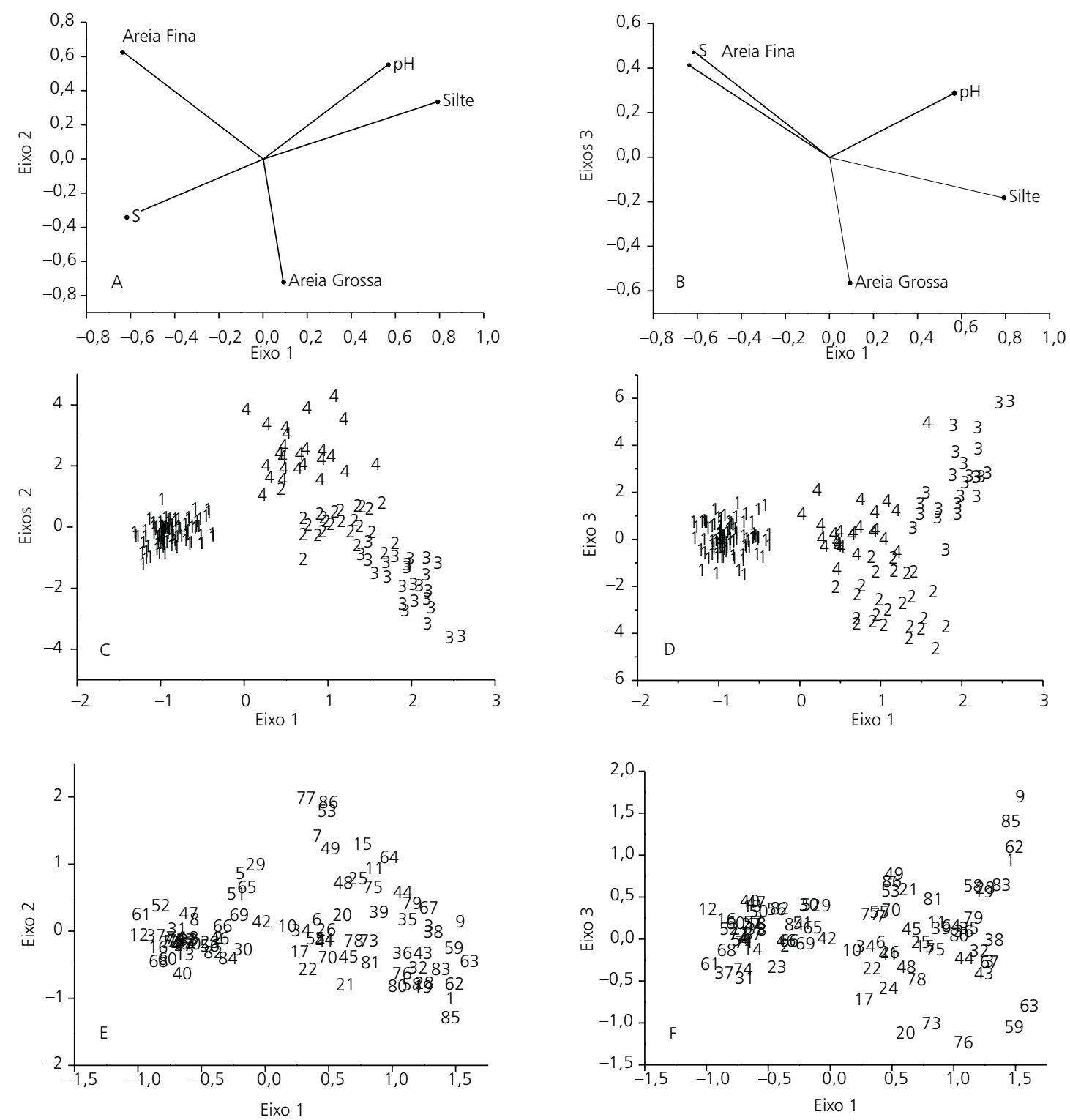

Fig. 4 - Biplot das variáveis texturais (areia grossa, areia fina, silte e argila) e químicas ( $\mathrm{pH}$ e $\mathrm{S}=$ soma das bases) do solo (A e B), escores das amostras (C e D, em que: 1 = Jaburuna, 2 = Baixa Fria, 3 = Carrasco e 4 = Estrondo) e escores das espécies (E e F) obtidos através da análise de correspondência canônica (CCA) com as amostras da vegetação e do solo das quatro áreas de carrasco estudadas no planalto da Ibiapaba, CE. Os nomes das espécies representadas por códigos, estão relacionados na Tabela 3.

Quando a área amostral de 0,25 ha aumentou para 1 ha, em Jaburuna, aumentou em 30\% (22) a riqueza de espécies e em $20 \%$ (6) a riqueza de famílias. Em 0,25 ha, quase 1/3 das espécies da amostra de Jaburuna não foi amostrado, mascarando a riqueza daquela vegetação. Em Jaburuna, o índice de diversidade de Shannon na amostra de 1 ha foi 3,161 nats/ind e na subamostra de 0,25 ha foi 3,070 nats/ind.

Não houve diferença estatisticamente significativa entre elas (Tabela 4), mostrando que a subamostra de 0,25 ha no carrasco de Jaburuna pode ter subestimado a riqueza, mas não subestimou a diversidade. 
TABELA 4

Comparação da diversidade de Shannon (H') entre áreas de carrasco no planalto da Ibiapaba. Valores seguidos por letras iguais não diferiram estatisticamente $(p \leq 5 \%)$.

\begin{tabular}{|c|c|}
\hline Localidades & H' $^{{ }^{\prime}}$ \\
\hline Jaburuna & $3,161^{\text {a }}$ \\
\hline Subamostra de Jaburuna & $3,070^{\text {ac }}$ \\
\hline Baixa Fria & $3,033^{\text {ac }}$ \\
\hline Carrasco & $2,866^{\text {bd }}$ \\
\hline Estrondo & $2,987^{\text {bc }}$ \\
\hline
\end{tabular}

A diversidade encontrada em 1 ha de carrasco em Jaburuna foi maior que a encontrada em Carrasco e Estrondo (Tabela 4). Considerando a subamostra de 0,25 ha em Jaburuna, apenas a diversidade da localidade Carrasco foi estatisticamente menor (Tabela 4). Na amostra de 1 ha, a riqueza aumentou muito, mas o índice de diversidade não, confirmando a baixa equabilidade indicada pela análise estrutural. Isso significa que, no carrasco, embora haja riqueza específica elevada, umas poucas espécies concentram a maior parte da abundância.

O carrasco do planalto da Ibiapaba é constituído predominantemente por espécies arbustivas microfanerofíticas de caules finos. Apresenta grande variabilidade espacial na composição florística e na abundância das populações. Ocorre grande concentração de dominância (baixa equabilidade) e as espécies mais abundantes diferem de um local a outro. As diferenças na distribuição e na abundância das espécies podem estar associadas a variações de variáveis ambientais. Variáveis edáficas, como a textura (variações dos teores de areia grossa, areia fina, argila e silte), a soma de bases e o $\mathrm{pH}$, exercem influência tanto sobre a distribuição das espécies quanto sobre a variação de sua abundância no espaço. Entretanto, a variação das variáveis edáficas testadas explicou apenas $13 \%$ da variância total dos dados, indicando que outras variáveis ambientais não testadas também devem exercer influência na variação da vegetação de carrasco no nordeste. Dentre essas outras variáveis, sugere-se que a proximidade geográfica com outros tipos de vegetação e a variação pluviométrica entre diferentes locais no planalto da Ibiapaba sejam as mais influentes. $\mathrm{O}$ tamanho das amostras das localidades de Baixa Fria, Carrasco e Estrondo
( 0,25 ha cada), quando comparado com o da amostra de Jaburuna (1 ha), subestimou a riqueza florística, mas não subestimou a diversidade.

Agradecimentos - Os autores agradecem aos Drs. A. T. Oliveira-Filho, L. S. Kinoshita e M. A. Figueiredo, pelas críticas e sugestões. Aos taxonomistas da UNICAMP, USP, UFC, Instituto de Botânica de São Paulo, Jardim Botânico do Rio de Janeiro, entre outros, pela identificação do material botânico. Ao Sr. Ilário Cândido Fernandes e Sra. Maria Graciema Daniel Cândido Fernandes, pela permissão para a realização dos trabalhos de campo em sua fazenda e pela hospedagem durante todo o levantamento de campo. À Geógrafa Leonor de Maria Rodrigues Melo, pela colaboração na coleta dos dados. À Fundação Cearense de Amparo à Pesquisa (FUNCAP) e à Fundação O Boticário de Proteção à Natureza (FBPN), pelo financiamento parcial deste trabalho. Ao programa PICD/CAPES, pela bolsa de pós-graduação concedida a F. S. Araújo.

\section{REFERÊNCIAS BIBLIOGRÁFICAS}

AB'SABER, A. N., 1974, O domínio morfoclimático semiárido das caatingas brasileiras. Instituto de Geografia/ USP, São Paulo (Série Geomorfologia, 43).

ANDRADE-LIMA, D. de, 1978, Vegetação. In: R. C. Lins. (ed.), Bacia do Parnaíba: aspectos fisiográficos. Instituto Joaquim Nabuco de Pesquisas Sociais, Recife, pp. 131135 (Série estudos e pesquisas, 9).

ANDRADE-LIMA, D. de, 1981, The caatingas dominium. Rev. Brasil. Bot., 4: 149-153.

ARAÚJO, F. S., 1992, Composição florística e fitossociologia da vegetação de carrasco, Novo Oriente - CE. Dissertação de Mestrado, UFRPE, Recife.

ARAÚJO, F. S., SAMPAIO, E. V. S. B., FIGUEIREDO, M. A., RODAL, M. J. N. \& FERNANDES. A. G., 1998a, Composição florística da vegetação de carrasco, Novo Oriente, CE. Rev. Brasil. Bot., 21: 105-116.

ARAÚJO, F. S., SAMPAIO, E. V. S. B., RODAL, M. J. N. \& FIGUEIREDO, M. A., 1998b, Organização comunitária do componente lenhoso de três áreas de carrasco em Novo Oriente - CE. Rev. Brasil. Biol., 58: 85-95. 
ARAÚJO, F. S. \& MARTINS, F. R., 1999, Fisionomia e organização da vegetação do carrasco no planalto da Ibiapaba, estado do Ceará. Acta. bot. bras, 13: 1-13.

ARAÚJO, F. S., 1998, Estudos fitogeográficos do carrasco no nordeste do Brasil. Tese de Doutorado, UNICAMP, Campinas.

CAIN, S. A. \& CASTRO, G. M. O., 1959, Manual of vegetation analysis. Hafner, New York.

CURTIS, J. T. \& MCINTOSH, R. P., 1950, The interrelations of certain analytic and synthetic phytosociological characters. Ecology, 31: 431-445.

CURTIS, J. T. \& MCINTOSH, R. P., 1951, An upland forest continuum in the prairie-forest border region of Wisconsin. Ecology, 32: 476-496.

EMBRAPA, 1979, Manual de métodos de análises de solo. SNLCS, Rio de Janeiro.

FERNANDES, A., 1990, Temas fitogeográficos. Stylos Comunicações, Fortaleza.

FERNANDES, A. \& BEZERRA, P., 1990, Estudo fitogeográfico do Brasil. Stylos Comunicações, Fortaleza.

FERRI, M. G., 1980, Vegetação brasileira. Editora Itatiaia/ EDUSP, São Paulo (Coleção Reconquista Brasil).

FIGUEIREDO, M. A., 1986, Vegetação. In: Atlas do Ceará (ed.), SUDEC, Fortaleza, pp. 24-25.

FONSECA, M. R., 1991, Análise da vegetação arbustiva-arbórea da caatinga hiperxerófila do noroeste do estado de Sergipe. Tese de Doutorado, UNICAMP, Campinas.

FUNCEME, 1995, Dados de pluviometria por faixa de anos - Estado do Ceará. Departamento de Apoio Tecnológico (DETEC), Fortaleza.

FURLEY, P. A. \& RATTER, J. A., 1988, Soil resources and plant communities of the central Brazilian cerrado and their development. J. Biogeogr., 15: 97-108.

GOMES, M. A. F., 1979, Padrões de caatinga nos Cariris Velhos, Paraíba. Dissertação de Mestrado, UFRPE, Recife.

HUTCHESON, K., 1970, A test for comparing diversities based on the Shannon formula. J. theor. Biol., 29: 151154.

KREBS, C. J., 1989, Ecological methodology. Harper Collins Pulishers, New York.

LINS, R. C., 1978, Bacia do Parnaíba: aspéctos fisiográficos. Instituto Joaquim Nabuco de Pesquisas Sociais (ed.), Recife. (Série estudos e pesquisas, 9.)

MAGURRAN, A. E., 1988, Ecological diversity and its measurement. Princeton University Press, New Jersey.

MARTINS, F. R., 1991, Estrutura de uma floresta mesófila. Editora da UNICAMP, Campinas, SP (Série teses).
MUELLER-DOMBOIS, D. \& ELLENBERG, H., 1974, Aims and methods of vegetation ecology. John Wiley \& Sons, New York.

NIMER, E., 1989, Climatologia do Brasil. 2a ed. IBGESUPREN (Fundação IBGE-SUPREN, Recursos Naturais e Meio Ambiente), Rio de Janeiro.

RAUNKIAER, C., 1934, The life forms of plants and statistical plant geography. Being the collected papers of C. Raunkiaer. Claredon Press, Oxford.

RIZZINI, C. T., 1997, Tratado de fitogeografia do Brasil. 2 ed. Âmbito Cultural Edições Ltda., Rio de Janeiro.

RODAL, M. J. N., 1992, Fitossociologia da vegetação arbustivo-arbórea em quatro áreas de caatinga em Pernambuco. Tese de Doutorado, UNICAMP, Campinas.

ROMARIZ, D. A., 1974, Aspectos da vegetação do Brasil. IBGE, Rio de Janeiro.

SAMPAIO, E. V. S. B., 1995, Overview of the Brazilian caatinga. In: S. H. Bullock, H. A. Mooney \& E. Medina, Seasonally dry tropical forests. University Press, Cambridge, pp. 35-63.

SHAFER, C. L., 1990, Nature reserves: island theory and conservation practice. Smithsonian Institution Press, Washington.

SHEPHERD, G. J., 1995, FITOPAC 1. Manual do usuário. Departamento de Botânica, Universidade Estadual de Campinas, Campinas.

SOKAL, R. R. \& ROHLF, F. J., 1995, Biometry. W. H. Freeman and Company, New York.

SOUZA, M. J. N., 1988, Contribuição ao estudo das unidades morfo-estruturais do estado do Ceará. Rev. de Geologia, 1: 73-91.

STEARNS, F., 1951, The composition of the sugar maplehemlock-yellow birch association in northern Wisconsin. Ecology, 32: 245-261.

SUDEC, 1980, Levantamento de reconhecimento semidetalhado dos solos de região natural da Ibiapaba. Fortaleza, CE.

SUDENE, 1990, Dados pluviométricos mensais do nordeste: v. 1 - Ceará. Recife (Série pluviométrica, 3).

ter BRAAK, C. J. F. (1987-1992), CANOCO - a FORTRAN program for Canonical Community Ordenation. Microcomputer Power, Ithaca, New York, USA. 